\title{
REVIEW
}

\section{Interplay between Brain Pericytes and Endothelial Cells in Dementia}

\author{
Tessa V. Procter, ${ }^{*}$ Anna Williams, ${ }^{* \dagger}$ and Axel Montagne ${ }^{\dagger \dagger}$
}

From the Centre for Regenerative Medicine, ${ }^{*}$ Institute for Regeneration and Repair, Edinburgh BioQuarter, UK Dementia Research Institute, ${ }^{\dagger}$ Edinburgh Medical School, and Centre for Clinical Brain Sciences, ${ }^{\ddagger}$ University of Edinburgh, Edinburgh, United Kingdom

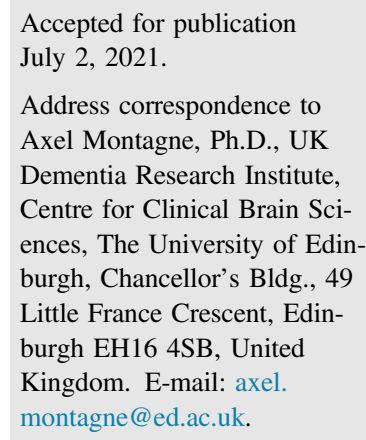

\begin{abstract}
Prevalence of dementia continues to increase because of the aging population and limited treatment options. Cerebral small vessel disease and Alzheimer disease are the two most common causes of dementia with vascular dysfunction being a large component of both their pathophysiologies. The neurogliovascular unit, in particular the blood-brain barrier (BBB), is required for maintaining brain homeostasis. A complex interaction exists among the endothelial cells, which line the blood vessels and pericytes, which surround them in the neurogliovascular unit. Disruption of the BBB in dementia precipitates cognitive decline. This review highlights how dysfunction of the endothelial-pericyte crosstalk contributes to dementia, and focuses on cerebral small vessel disease and Alzheimer disease. It also examines loss of pericyte coverage and subsequent downstream changes. Furthermore, it examines how disruption of the intimate crosstalk between endothelial cells and pericytes leads to alterations in cerebral blood flow, transcription, neuroinflammation, and transcytosis, contributing to breakdown of the BBB. Finally, this review illustrates how cumulation of loss of endothelial-pericyte crosstalk is a major driving force in dementia pathology. (Am J Pathol 2021, 191: 1917-1931; https://doi.org/10.1016/ j.ajpath.2021.07.003)
\end{abstract}

Dementia is characterized by a gradual cognitive impairment with additional symptoms, such as depression and changes to balance and gait. ${ }^{1}$ Alzheimer disease (AD) is the most common cause of dementia followed by cerebral small vessel disease (cSVD), the leading cause of vascular dementia. ${ }^{2}$ Both diseases can occur in conjunction, thereby worsening the disease risk. ${ }^{3}$ Mounting evidence supports the role of vascular dysfunction in $\mathrm{AD}$, with many patients also exhibiting signs of cSVD. ${ }^{3,4}$ cSVD encompasses a group of pathologic conditions that affect the perforating cerebral venules, capillaries, and small arterioles, leading to white and gray matter damage in the central nervous system (CNS). ${ }^{5}$ Sporadic forms of AD and cSVD share cardiovascular risk factors, ${ }^{2}$ suggesting that vascular dysfunction is a major contributing factor in both. Vascular dysfunction can take many forms that involve many cells comprising the neurogliovascular unit (NVU) and include disruption of the blood-brain barrier (BBB), which plays a vital role in maintaining cerebral homeostasis. However, this review focuses on how the complex interactions between endothelial cells lining the blood vessels and pericytes closely apposed to the endothelial cells on the abluminal side contribute to $\mathrm{BBB}$ disruption, a central pathologic mechanism in these two important dementias.

\footnotetext{
Supported by the UK Dementia Research Institute, which receives its funding from DRI Ltd, the Medical Research Council, the Alzheimer's Society, and Alzheimer's Research UK (A.M. and A.W.), grant MR/T015594/1 from the Medical Research Council and the Multiple Sclerosis Society UK (A.W.), and grant 203913/Z/16/Z from the Wellcome Trust-funded Edinburgh Clinical Academic Track Veterinary clinical lectureship (T.V.P.).

Disclosure: None declared.

This article is part of a review series on small blood vessel disease in the brain addressing current knowledge, new mechanisms, biomarkers, and therapeutic approaches.
} 


\section{The BBB in Health}

Blood vessels throughout the body are normally partly permeable to allow the exchange of nutrients, solutes, and chemical signals between tissue and the blood, which are vital for keeping cells alive. However, the brain microenvironment is different from the rest of the body and requires tighter control provided by the BBB. Substance movement can occur paracellularly (between endothelial cells) or transcellularly (across endothelial cells), and the BBB tightly regulates the two types of substance movement via junctional complexes between endothelial cells and through expression of membrane receptors and pumps, with limited passive diffusion. ${ }^{6}$ Furthermore, the BBB allows separation of peripheral and central neurotransmitters, avoiding potential cross-signaling. ${ }^{6}$ Pathogens, plasma proteins, and immune cells from the blood can have severe detrimental consequences if present within the brain, and disruption to the BBB is a major component of many neurologic diseases, including $\mathrm{AD}$ and $\mathrm{CSVD}$.

The BBB comprises various components, commonly referred to as the NVU (Figure 1), including endothelial cells, pericytes, basement membrane, astrocyte end-feet, and surrounding oligodendrocytes and microglia, and links to neurons in a process called neurovascular coupling in which increased neuronal activity leads to increased blood flow to that area. ${ }^{6}$ The NVU is unique in that its cellular components are in close and sometimes direct contact with one another, allowing for intimate crosstalk. ${ }^{6}$ Endothelial cells line the blood vessels, and pericytes are mesenchymalderived cells on the brain side of endothelial cells. Pericytes are found encircling capillaries as well as precapillary arterioles and postcapillary venules, whereas vascular smooth muscle cells (VSMCs) are found in larger vessels. ${ }^{8}$ Collectively, pericytes and VSMCs are known as vascular mural cells (VMCs).

In human tissue, pericytes form two subtypes with enriched gene expression of either transmembrane transporters or extracellular matrix (ECM) regulation genes. ${ }^{9}$ In addition, pericyte morphology plays an important role in maintaining $\mathrm{BBB}$ integrity because pericytes in the median eminence (ME), where BBB leakage naturally occurs, have a more irregular shape and less prominent nucleus compared with cortical tissue with a functional BBB. ${ }^{10}$ A study of pericytes in the mouse cortex found that, depending on their location along the vascular tree, pericytes have different phenotypes. ${ }^{11}$ Grant et $\mathrm{al}^{11}$ subdivided pericytes into ensheathing pericytes located on larger diameter precapillary arterioles with shorter cell lengths and $\alpha$-smooth muscle actin ( $\alpha$-SMA), and mesh pericytes and thin-strand pericytes located on smaller diameter capillaries with longer cell lengths, and no detectable $\alpha$-SMA. They argue that
Cognitively unimpaired Healthy BBB

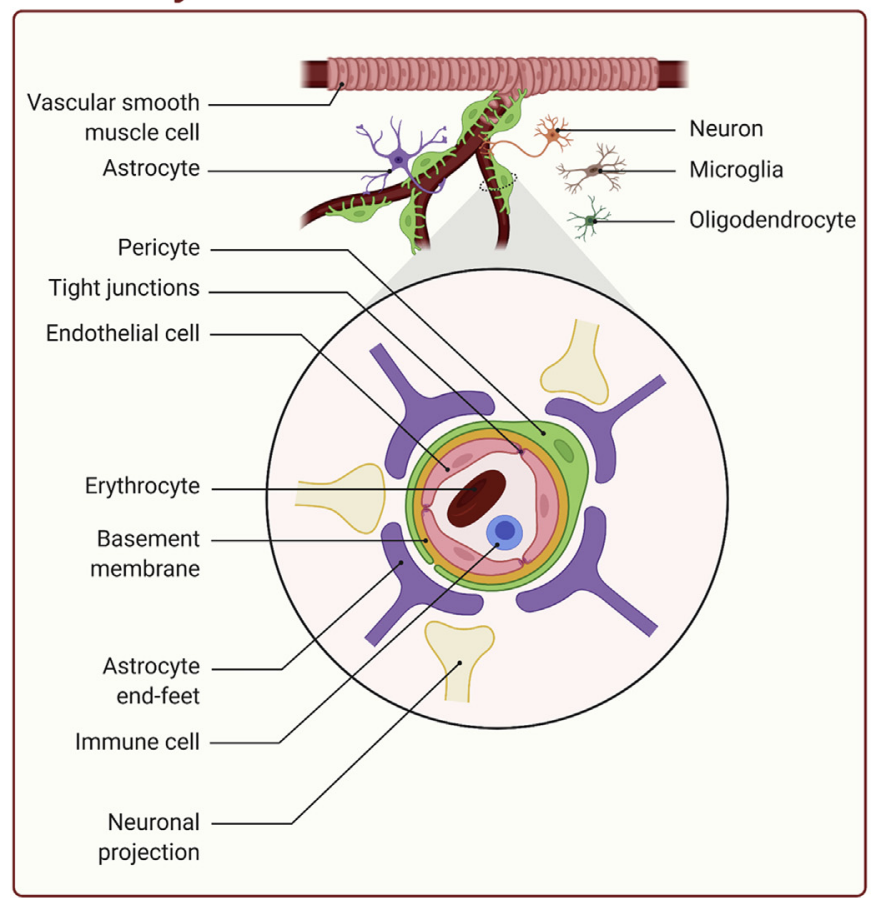

\section{CSVD and $A D$}

\section{BBB Breakdown}

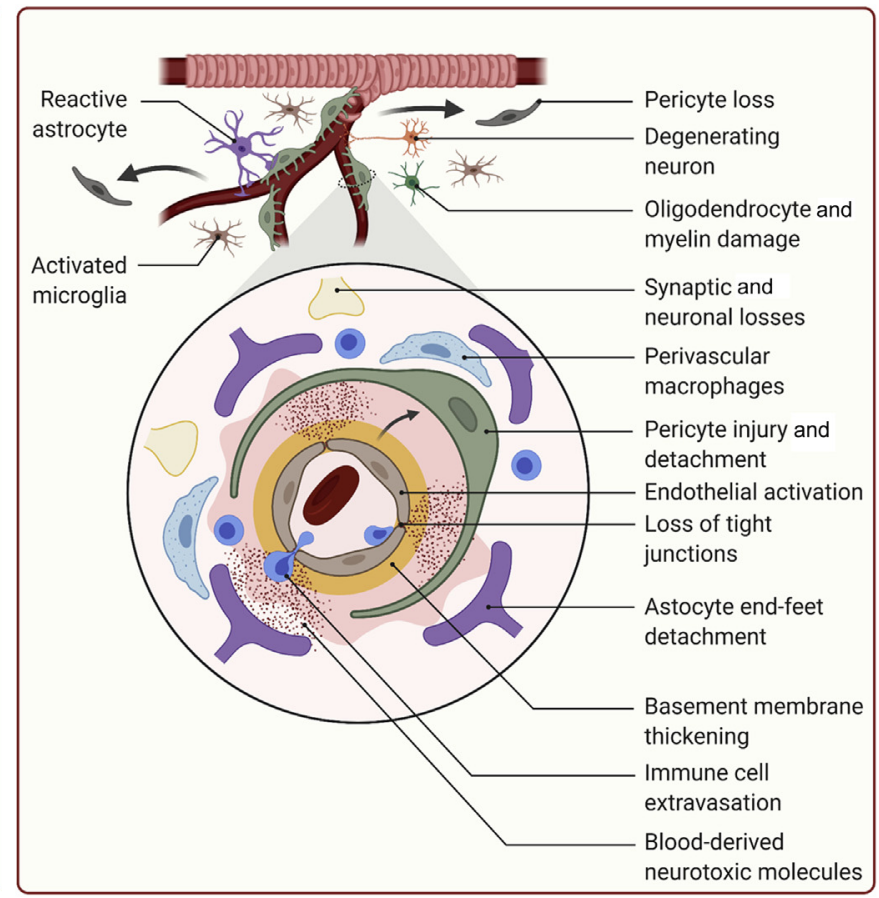

Figure 1 Components of the neurogliovascular unit (NVU) and changes that occur in cerebral small vessel disease (CSVD) and Alzheimer disease (AD). The components of the NVU play an important role in maintaining the blood-brain barrier (BBB) in health. In dementia, changes, in particular to the endothelial cells and pericytes, lead to loss of function and BBB breakdown. Subsequently, the surrounding astrocytes, neurons, and oligodendrocytes get damaged, contributing to pathologic findings. Figure generated with Biorender.com (Biorender, Toronto, Ontario, Canada). 
ensheathing pericytes are transitional mural cells with characteristics of both VSMCs and pericytes, whereas mesh and thin-strand pericytes comprise the capillary pericytes. ${ }^{11}$ Despite a morphologic continuum in mice, there appears to be a more distinct difference in gene expression between VSMCs and pericytes in humans. ${ }^{9}$ Much of the literature makes no distinctions between pericyte subtypes because of not assessing morphologic differences. Furthermore, platelet-derived growth factor receptor $\beta$ (PDGFR- $\beta$ ), which is expressed in all pericyte subtypes, ${ }^{11}$ is frequently used as a pericyte marker. However, other CNS cell types have also been found to express PDGFR- $\beta$, such as perivascular fibroblast-like cells ${ }^{12}$ which adds further complexity to distinguishing different pericytes subtypes and from surrounding perivascular cells.

Endothelial cells and pericytes have direct contact through gap junctions, which allow ionic currents to pass between their cytoplasms, and through adhesion plaques, which are involved in tethering pericytes to endothelial cells. ${ }^{13}$ In addition, pericyte-endothelial direct connections are made through peg-and-socket junctions where evaginations interdigitate and provide a form of pericyte-endothelial anchorage. ${ }^{10,13}$ It is the endothelial cells of the NVU that are the mainstay of the BBB, and together the other components of the NVU help regulate it. ${ }^{6}$

Endothelial cells of the BBB possess unique properties reflected in their specialized gene expression profile. ${ }^{10}$ It is their junctional proteins in particular that confer the barrier's characteristic properties of limiting paracellular permeability. Brain endothelial cells have a higher expression of certain junctional proteins localized at the cell-cell junctions compared with endothelial cells from nonneural tissues. ${ }^{14}$ Endothelial cells express three types of junctional proteins that dimerize between two cells to form junctional complexes: adherens junctions (eg, vascular endothelial cadherin), tight junctions [eg, claudin-5 (CLDN-5) and occludin], and gap junctions (eg, connexins). ${ }^{15}$ CLDN-5 is highly expressed in brain endothelial cells ${ }^{14}$ and, importantly, is important in limiting movement of small molecules $(<800 \mathrm{Da})$ across the BBB. ${ }^{16}$

In rats, the BBB forms at the initial stages of embryonic development, as early as E11 to E17. ${ }^{17}$ Already at this stage, endothelial cells and pericytes are seen in association, and both cell types invade the intraneural tissue to begin BBB formation. Endothelial cells initially possess fenestrations, which are lost following migration. ${ }^{17}$ The close contact and synchronous migration of endothelial cells and pericytes during BBB formation are suggestive of the essential role of pericyte-endothelial cell interaction in BBB formation. Furthermore, mouse models deficient in pericytes do not survive to birth and have marked cerebral vasculature abnormalities that lack features of a mature functional BBB. ${ }^{18}$ After the initial endothelial cell and pericyte migration, the $\mathrm{BBB}$ continues to mature with recruitment of other cell types to form the NVU (Figure 1). ${ }^{17}$ In addition, endothelial-pericyte communication in adulthood is essential to maintain a functional $\mathrm{BBB}$ as acute ablation of pericytes results in BBB breakdown. ${ }^{19}$ A mature BBB is crucial in maintaining brain homeostasis, ${ }^{6}$ and its disruption is involved in numerous diseases. ${ }^{7,20}$

\section{Clinical Evidence of BBB Disruption in AD and CSVD}

The critical role of the BBB and its integrity in health is indicted by the fact that BBB breakdown is a component of many neurologic disorders, ranging from inflammatory to neoplastic to neurodegenerative conditions. ${ }^{7,20}$ Loss of or reduced barrier function allows for ingress of toxic blood components, inflammatory cells, and pathogens, which disrupt the delicate brain environment and lead to pathologic events (Figure 1). In recent years, there has been mounting evidence of the involvement of vascular pathologic mechanisms in addition to the amyloid cascade in the development of $\mathrm{AD}^{21}$ (Table 1). ${ }^{21-75}$ For example, a large autopsy study found that $79.9 \%$ of patients have vascular pathologic signs. ${ }^{46}$ In addition, genome-wide association studies found a large number of AD-related genes in vascular cells. ${ }^{9}$ Evidence of BBB disruption has been found in postmortem tissue from patients with $\mathrm{AD}$ and $\mathrm{cSVD}$. $^{28,31}$ In particular, patients with $\mathrm{AD}$ and APOE4 have increased deposition of the blood component fibrin(ogen) perivascularly, ${ }^{31}$ suggestive of leakage.

Clinical diagnosis of AD or cSVD is supported through visualization of changes on magnetic resonance imaging (MRI) (Table 1), with BBB leakage detectable with dynamic contrast-enhanced MRI, and intravenous injection of gadolinium-based tracers. Gadolinium tracer leakage is seen in $\mathrm{AD},{ }^{42}$ APOE4 carriers at risk for $\mathrm{AD},{ }^{44}$ and $\mathrm{cSVD} .{ }^{40} \mathrm{In}$ addition, many of the MRI signs, such as white matter hyperintensities (WMHs), lacunes, microbleeds, and infarcts, are shared between the diseases, emphasizing their overlap. ${ }^{3,20,46,76}$ These lesions, which indicate tissue damage, ${ }^{76,77}$ originate, to a large degree, from the disruption of the BBB. ${ }^{40,62}$

WMHs on neuroimaging are associated with a threefold increased risk of developing dementia and significantly associated with vascular dementia ${ }^{78}$ and $\mathrm{AD} .^{3,78}$ In patients with CSVD, occurrence of BBB breakdown in WMHs is indicated by increased gadolinium leakage compared with that in the surrounding normal-appearing white matter, ${ }^{40}$ and the degree of BBB breakdown positively correlates with WMH volume. ${ }^{41}$ Furthermore, disruption to the BBB and leakage has also been found in the normal-appearing white matter of patients with cSVD, indicating more generalized vascular dysfunction ${ }^{41}$ and demonstrating the importance of $\mathrm{BBB}$ breakdown as a core pathologic mechanism in dementia. Of interest, BBB leakage in the hippocampus of patients with mild cognitive impairment correlates with cerebrospinal fluid (CSF) levels of soluble 
Table 1 Evidence of Vascular Pathologic Findings and Crossover in CSVD and AD

\begin{tabular}{|c|c|c|c|c|c|c|c|c|}
\hline \multirow[b]{2}{*}{ Findings } & \multicolumn{4}{|l|}{ Clinical } & \multicolumn{4}{|c|}{ Preclinical models } \\
\hline & \multicolumn{2}{|l|}{ CSVD } & \multicolumn{2}{|l|}{$A D$} & \multicolumn{2}{|l|}{ CSVD } & \multicolumn{2}{|l|}{$A D$} \\
\hline $\begin{array}{l}\text { Amyloid plaques in tissue } \\
\text { and cells } \\
\text { Angiogenic changes and } \\
\text { markers (VEGF and } \\
\text { TGF- } \beta \text { ) }\end{array}$ & $\begin{array}{l}\text { No } \\
\text { evidence }\end{array}$ & & Evidence & $7,21,22$ & $\begin{array}{l}\text { No } \\
\text { evidence }\end{array}$ & & Evidence & 23 \\
\hline Tissue and cells & Evidence & 24 & Evidence & $24-26$ & Unknown & & Unknown & \\
\hline Biofluids & Evidence & 27 & Evidence & 27 & Unknown & & Unknown & \\
\hline \multicolumn{9}{|l|}{$\begin{array}{l}\text { BBB leakage [fibrin(ogen), } \\
\text { IgG, tracer, albumin, } \\
\text { ANGPT2] }\end{array}$} \\
\hline Tissue and cells & Evidence & $28-30$ & Evidence & $21,24,31,32$ & Evidence & 33,34 & Evidence & $19,20,35-38$ \\
\hline Biofluids & Unknown & & Evidence & 21,39 & Evidence & 33 & Unknown & \\
\hline Neuroimaging & Evidence & $7,40,41$ & Evidence & $7,21,42-44$ & Evidence & 33,45 & Evidence & 38 \\
\hline $\begin{array}{l}\text { Enlarged PVS in tissue and } \\
\text { cells }\end{array}$ & Evidence & 29 & No evidence & & Unknown & & No evidence & \\
\hline \multicolumn{9}{|l|}{ Infarcts } \\
\hline Tissue and cells & Evidence & 46 & Evidence & 46 & Evidence & 45 & Unknown & \\
\hline Neuroimaging & Evidence & 7,46 & Evidence & 3 & Unknown & & Unknown & \\
\hline $\begin{array}{l}\text { Lacunes in tissue and cells } \\
\text { Microbleeds }\end{array}$ & Evidence & 29,46 & Evidence & 46 & Unknown & & Unknown & \\
\hline Tissue and cells & Evidence & 46 & Evidence & 46 & Evidence & 45 & Evidence & 18 \\
\hline Neuroimaging & Evidence & 47 & Evidence & $21,46,48$ & Unknown & & Unknown & \\
\hline \multicolumn{9}{|l|}{$\begin{array}{l}\text { Neuroinflammation } \\
\text { (MMPs, CAMs, CypA, } \\
\text { and RAGE) }\end{array}$} \\
\hline Tissue and cells & Unknown & & Evidence & $9,31,49$ & Evidence & 50 & Evidence & $\begin{array}{c}35,37,38 \\
51-53\end{array}$ \\
\hline $\begin{array}{l}\text { Biofluids } \\
\text { Parenchymal changes and } \\
\text { WMHs (myelin loss, } \\
\text { gliosis, and neuronal } \\
\text { loss) }\end{array}$ & Evidence & 54,55 & Evidence & $31,44,56-58$ & Evidence & 33 & Unknown & \\
\hline Tissue and cells & Evidence & 29,59 & Evidence & 21,22 & Evidence & $33,50,60$ & Evidence & 36,38 \\
\hline Neuroimaging & Evidence & $\begin{array}{r}7,40,41 \\
60,61\end{array}$ & Evidence & 3,62 & Evidence & 29,33 & Unknown & \\
\hline \multicolumn{9}{|l|}{ Pericyte loss (sPDGFR- $\beta$ ) } \\
\hline Tissue and cells & Unknown & & Evidence & $9,32,43$ & Unknown & & Evidence & 23 \\
\hline Biofluids & Unknown & & Evidence & $9,21,43,44$ & Unknown & & Unknown & \\
\hline $\begin{array}{l}\text { Transcytosis in tissue and } \\
\text { cells }\end{array}$ & Evidence & 63 & Evidence & 63 & Evidence & 64,65 & Evidence & 53,66 \\
\hline \multicolumn{9}{|l|}{$\begin{array}{l}\text { Vasoactive dysregulation } \\
\text { and CBF (NO and ET- } \\
\text { 1) }\end{array}$} \\
\hline Tissue and cells & Evidence & 67 & Evidence & $9,68,69$ & Evidence & 60,70 & Unknown & \\
\hline Neuroimaging & Evidence & 61 & Evidence & $20,21,42,71$ & Evidence & 45,50 & Evidence & 20,36 \\
\hline $\begin{array}{l}\text { Vessel and endothelial cell } \\
\text { change (instability, } \\
\text { junctional protein } \\
\text { changes, and } \\
\text { morphologic features) } \\
\text { in tissue and cells }\end{array}$ & Evidence & 60 & Unknown & & Evidence & $\begin{array}{c}50,60,64,65 \\
70,72,73\end{array}$ & Evidence & $\begin{array}{r}8,18,35,37,38 \\
53,66,74,75\end{array}$ \\
\hline
\end{tabular}

Examples from selected references of neuropathology are seen in tissue and biofluids, such as serum and cerebrospinal fluid, as well as on neuroimaging, such as magnetic resonance imaging.

AD, Alzheimer disease; ANGPT2, angiopoietin-2; CAMs, cellular adhesion molecules; CBF, cerebral blood flow; cSVD, cerebral small vessel disease; CypA, cyclophilin A; ET-1, endothelin-1; MMPs, matrix metalloproteinases; N0, nitric oxide; RAGE, receptor for advanced glycation end products; sPDGFR- $\beta$, soluble platelet-derived growth factor receptor $\beta ;$ TGF- $\beta$, transforming growth factor $\beta$; VEGF, vascular endothelial growth factor; WMHs, white matter hyperintensities. 
PDGFR- $\beta,{ }^{43,44}$ a marker of damaged pericytes, ${ }^{43}$ which prompts further consideration of their role in dementia.

\section{Loss of Pericyte-Endothelial Signaling and BBB Breakdown}

Pericytes directly encircle endothelial cells, and their vascular coverage is thought to positively correlate with barrier strength. ${ }^{79}$ There is much debate about the extent of cerebral pericyte-endothelial cell coverage, primarily because of the wide variety of ways of measuring it. Some studies use electron microscopy to define coverage as a percentage of endothelial cell encircled by pericytes, ${ }^{80}$ although more recent studies use PDGFR- $\beta$ immunofluorescence to define coverage as a percentage of the vessel area that is PDGFR- $\beta$-positive and assess the number of pericytes by counting PDGFR- $\beta$ - positive cell bodies. ${ }^{32,79}$ In addition, it is likely that coverage varies between organ and tissue location within the organ. ${ }^{9,81}$ A study of retinal and brain cortical tissue found that pericytes covered $85 \%$ of the capillary circumference in human and monkey retinas, but coverage was significantly less in monkey cortex. ${ }^{80}$ This study used electron microscopy to determine the extent of pericyte coverage, thereby examining very small areas and perhaps not detecting variation between blood vessels in different regions. Pericytes cover up to $80 \%$ of brain capillaries in the human cortex and hippocampus, as indicated by immunofluorescence. ${ }^{32}$ However, more recently, sequencing showed that the hippocampus has fewer pericytes than cortical tissue. ${ }^{9}$ In three regions of mouse brain, coverage was approximately $80 \%$, whereas in the spinal cord, pericyte coverage varied from $48 \%$ to $68 \%$, depending on location. ${ }^{79}$ Pericyte coverage is heterogeneous and dependent on subtype, which relates to vessel diameter, leading to variations in vessel coverage. In mice, ensheathing pericytes cover up to $95 \%$ of the vessel, whereas mesh and thin-strand pericytes cover $71 \%$ and $51 \%$, respectively. ${ }^{11}$ However, it is generally accepted that in the CNS a high proportion of endothelial cells are encircled by pericytes, hinting at the vital role they play in the NVU and regulation of the $\mathrm{BBB},{ }^{79,81}$ but the exact figures vary among species, brain regions, and measurement techniques. Of importance, pericyte coverage appears to be related to BBB leakage because naturally leaky capillaries of the ME have a reduced pericyte coverage in mice compared with cortical capillaries. ${ }^{10}$

Loss of pericyte coverage is part of normal aging, a major risk factor for dementia, in rodents ${ }^{82}$ and in humans. It is indicated by an increase in soluble PDGFR- $\beta$ in the CSF, ${ }^{43}$ which correlates with worse cognitive impairment. ${ }^{43}$ Loss of pericytes in disease appears greater than that of in normal aging, ${ }^{9,32}$ with patients with $\mathrm{AD}$ having up to a $60 \%$ reduction in pericyte number and 30\% reduction in capillary coverage when compared with controls, as indicated by PDGFR- $\beta$ immunostaining. ${ }^{32}$ Furthermore, a recent study found an overall reduction in VMCs and endothelial cells in patients with $\mathrm{AD}$, in particular a subtype of pericytes involved in regulating the ECM. ${ }^{9}$

The loss of pericytes may occur through disruption of the endothelial sphingosine-1-phosphate (S1P) receptor, which is involved in regulating pericyte vessel coverage ${ }^{83,84}$ by controlling $\mathrm{N}$-cadherin trafficking to the membrane needed for endothelial-pericyte adhesion. A reduction in S1P receptors occurs in $\mathrm{AD}$ brain tissue, ${ }^{85}$ and an S1P analogue, a ligand for the S1P receptor, reduces memory impairment in an AD mouse model. ${ }^{86}$ The neuroprotective effect of S1P is mediated by reducing amyloid- $\beta$ (A $\beta)$-induced neuronal apoptosis $^{87}$ and reducing levels of certain S1P isoforms in vascular dementia. ${ }^{88}$ In addition, dysregulation of S1P is implicated in neuroinflammation, ${ }^{88}$ another pathophysiologic component of AD and cSVD. ${ }^{89}$ Therefore, S1P and S1P receptor play a role in the pathophysiologic mechanisms of dementia by altering amyloid-induced apoptosis, neuroinflammation, and endothelial-pericyte adhesion.

Interestingly, recent evidence from a genetic form of vascular dementia, cerebral autosomal dominant arteriopathy with subcortical infarcts and leukoencephalopathy (CADASIL), has found no reduced pericyte coverage in patients or a mouse model. ${ }^{29}$ These patients harbor mutations in the NOTCH3 gene; therefore, the BBB disruption seen may be attributable to the requirement of NOTCH for adhesion of endothelial cells and VSMCs to the basement membrane, affecting vessel stability. ${ }^{90}$ In addition, pluripotent stem cell (iPSC)-derived VMCs in patients with CADASIL have reduced PDGFR- $\beta$ and can induce apoptosis in neighboring endothelial cells, leading to decreased blood vessel stability. This phenotype is specific to the vascular mural iPSCs because the endothelial iPSCs are able to form normal vessel networks. ${ }^{70}$ Furthermore, differentially expressed genes in the VMCs of patients with $\mathrm{AD}$ are similar to those seen in CADASIL, and ECM maintenance in $\mathrm{AD}$ involves loss of a pericyte subtype. ${ }^{9}$ Together, these data suggest that BBB disruption in dementia occurs not only through loss of pericyte coverage and endothelial-pericyte contact but also through ECM disruption and/or loss of PDGFR- $\beta$ signaling (Figure 2).

Platelet-derived growth factor $\beta$ (PDGF- $\beta$ )/PDGFR- $\beta$ signaling is one of the most studied and important pathways in pericyte-endothelial crosstalk. Brain endothelial cells are enriched for and secrete PDGF- $\beta,{ }^{91}$ which binds to pericytespecific PDGFR- $\beta .^{92}$ Most knowledge of the PDGF- $\beta$ / PDGFR- $\beta$ signaling pathway stems from studying $P d g f b$ - or $P d g f r b$-null embryos (because these mice do not survive to birth $^{18}$ ) or postnatally in hypomorphic $P d g f b^{\text {ret/ret }}$ - or Pdgfrbdeficient models. Of importance, these models have helped further the understanding of possible mechanisms that contribute to BBB breakdown seen in cSVD and AD. ${ }^{40,46}$ As mentioned above, clinical data from patients with dementia indicate an increase in soluble PDGFR- $\beta$ in the CSF, ${ }^{43}$ supporting the involvement of PDGF- $\beta /$ PDGFR- $\beta$ signaling in disease pathology. Further evidence of the 


\section{Cognitively unimpaired Healthy pericyte-endothelial crosstalk

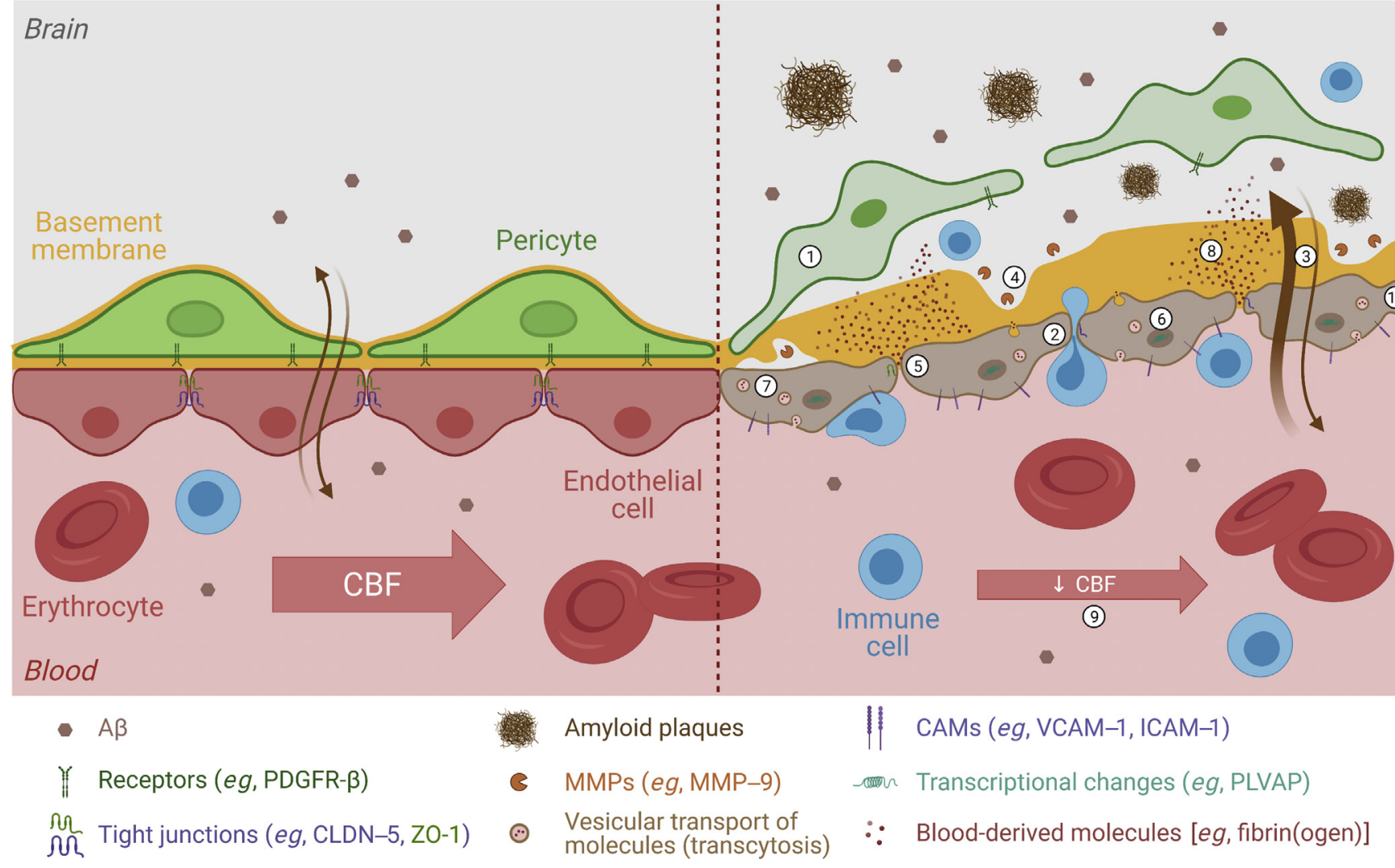

Figure 2 Loss of pericyte-endothelial crosstalk in cerebral small vessel disease and Alzheimer disease. Disruption to endothelial-pericyte signaling leads to a wide variety of changes: (1) pericyte loss; (2) endothelial cell activation and extravasation of immune cells; (3) loss of balanced amyloid- $\beta$ (A $\beta$ ) transport caused by increased receptor for advanced glycation end products and loss of low-density lipoprotein receptor-related protein 1 (LRP1), leading to A $\beta$ buildup in the brain; (4) loss of LRP1 also contributes to loss of inhibition of the cyclophilin A-matrix metalloproteinase (MMP)-9 pathway, leading to extracellular matrix/basement membrane breakdown by MMPs; (5) MMP activation contributes to loss of junctional proteins, changes in organization, and widening junctional gap between endothelial cells; (6) transcriptional changes that lead to a more venous phenotype; (7) reduced major facilitator superfamily domain containing 2a, which contributes to increased transcytosis; (8) BBB breakdown and ingress of neurotoxic substances such as fibrin(ogen) into the brain; (9) dysregulation of vasoactive substances (eg, nitric oxide) and subsequent reduced cerebral blood flow (CBF); and (10) morphologic changes to endothelial cells with cellular hyperplasia and aberrant angiogenesis. Figure generated with Biorender.com (Biorender, Toronto, Ontario, Canada). CAMs, cellular adhesion molecules; CLDN-5, claudin-5; ICAM-1, intercellular adhesion molecule 1 ; PDGFR- $\beta$, platelet-derived growth factor receptor $\beta$; PLVAP, plasmalemma vesicle-associated protein; VCAM-1, vascular cell adhesion molecule 1; Z0-1, zonula occludens protein 1.

clinical importance of disruption to the PDGF- $\beta$ /PDGFR- $\beta$ signaling pathway can be seen after surgically-induced large vessel stroke in adult $P d g f r b$ knockout mice, which indicates reduced pericyte coverage, significantly larger stroke lesions, and more BBB leakage, as compared with controls. This phenotype is significantly rescued with the preservation of PDGFR- $\beta$ expression in pericytes. ${ }^{93}$ Most importantly, these models allow us to understand the importance of endothelialpericyte crosstalk in maintaining BBB integrity.

In human $\mathrm{AD}$, brain areas with reduced pericyte coverage of vessels show increased fibrin(ogen) and IgG extravasation demonstrating BBB leakage, ${ }^{32}$ and similar pathologic changes are seen in $\operatorname{cSVD}^{30}$ (Figure 2). The findings of BBB impairment in patients with reduced pericyte vessel coverage are supported by reduced pericyte coverage in the naturally leaky $\mathrm{ME}^{10}$ and studies in rodents using pericyte-deficient mice seen by dextran tracer leakage around pericyte-deficient blood vessels, which worsens with increasing age, ${ }^{35}$ a major risk factor for cSVD and AD dementias. In these mice, fibrin(ogen) and IgG leakage can occur with as little as $20 \%$ reduction in pericyte coverage. ${ }^{35}$ Pericyte degeneration is also associated with accumulation of fibrin(ogen) in the white matter of pericyte-deficient mice. ${ }^{36}$ Interestingly, fibrin(ogen) accumulation is much greater in the white matter regions of the brain compared with gray matter. Furthermore, fibrin(ogen) deposition in the white matter leads to loss of myelin, oligodendrocytes, and neuronal axons ${ }^{36}$ similar to changes seen in patients with $\mathrm{AD}$ and $\mathrm{CSVD},{ }^{59}$ and $\mathrm{CSVD}$ rat models. ${ }^{33}$ The loss of oligodendrocytes may be, in part, attributable to the reduced vascular density and corresponding reduction in blood flow, leading to increased levels of hypoxia in white matter regions compared with that in the gray matter. ${ }^{36}$ This study highlights that 
regional differences in pericyte coverage within the CNS likely contribute to the differences in tissue susceptibility in dementia.

In addition to overexpression of the $A \beta$ precursor protein in transgenic mice, pericyte deficiency leads to reduced brain $A \beta$ clearance mediated by low-density lipoprotein receptor-related protein 1 (LRP1). The reduction of LRP1mediated clearance is not through changes in pericyte LRP1 expression but through reduction in pericyte numbers, ${ }^{23}$ thus demonstrating an important role for pericytes in $A D$ pathology, and in particular, limiting the formation of $A \beta$ plaques. Endothelial cell LRP1 is important in maintaining BBB integrity; loss of endothelial LRP1 leads to BBB leakage, neuronal loss, and altered cognition in mice. This phenotype is attributable to cyclophilin A (CypA) matrix metalloproteinase (MMP)-9 pathway activation (discussed subsequently) and can be rescued by CypA inhibition or LRP1 reexpression. ${ }^{38}$ Loss of pericytes as well as changes to pericyte and endothelial protein expression likely affect not only BBB leakage and toxin clearance but also cerebral blood flow.

\section{Pericyte-Endothelial Crosstalk Controls Cerebral Blood Flow}

The integrity of the brain vasculature is important in maintaining perfusion to and oxygenation of the brain, which are vital because of a high metabolic demand and low energy storage capacity of the brain. ${ }^{94}$ There is disparity in the literature as to whether pericytes are able to directly control vessel diameter and hence blood flow. ${ }^{95-97}$ It is thought that pericytes lack contractile $\alpha$-SMA and therefore have the ability to contract in response to stimuli. However, the presence of $\alpha$-SMA in pericytes could be underreported because of filamentous-actin fixation or low cellular expression. ${ }^{11,98,99}$ Studies have found that retinal and brain pericytes possess $\alpha$-SMA, ${ }^{98}$ and the ensheathing pericyte subtype is $\alpha$-SMA-positive. ${ }^{11}$ Ensheathing pericytes respond to sensory stimuli, and vasodilate before arterioles via nitric oxide and prostaglandin $\mathrm{E}_{2} .{ }^{95}$ Similar results are seen in another mouse model mediated by endothelialsecreted epoxyeicosatrienoates, ${ }^{100}$ demonstrating endothelial-pericyte crosstalk in cerebral blood flow control. Disparities in the literature may be attributable to inconsistencies in terminology with first- to fourth-order branches from perforating arterioles termed capillaries instead of precapillary arterioles and their associated ensheathing pericytes being termed $\alpha$-SMA-positive VSMCs. When different subtypes of pericytes are taken into account, studies appear to agree that precapillary ensheathing pericytes are able to regulate blood flow in vivo. ${ }^{11}$

However, whether the capillary pericytes (mesh and thinstrand pericytes) are able to modulate cerebral blood flow is debatable. ${ }^{11,96,101}$ Cerebral capillary pericytes express the smooth muscle protein, myosin heavy chain, indicating some contractile ability. ${ }^{102}$ Furthermore, recent studies have found that capillary pericytes modulate blood vessel diameter more slowly after direct in vivo stimulation compared with surrounding ensheathing pericytes. ${ }^{101}$ Similar results were seen in retinal capillaries after direct stimulation, but this was not replicated in the cortical capillaries. ${ }^{102}$ One hypothesis to explain this is that capillary pericytes require a stronger or different stimulus to respond. ${ }^{11,102}$ Furthermore, imaging techniques may contribute to the ability to detect capillary diameter changes, and regional differences may occur; cerebral in vivo studies are currently limited to the cortex. Despite the debate over the ability of capillary pericytes to modulate cerebral blood flow, there are strong data supporting the role of ensheathing pericytes, particularly at vessel junctions, ${ }^{102}$ in controlling blood flow response to NVU stimuli.

Reduction in cerebral blood flow occurs in the gray matter of patients with cognitive impairment, ${ }^{61,71}$ who, as mentioned above, have reduced pericyte coverage in these regions. ${ }^{43}$ The reduction in cerebral blood flow positively correlats with loss of pericytes, demonstrating that pericyte degeneration in dementia ${ }^{32,43}$ is likely to contribute to changes to cerebral blood flow. This theory is supported by data in pericyte-deficient mice in which cerebral blood flow is reduced, particularly in the white matter. ${ }^{36}$ Furthermore, acute pericyte ablation after diphtheria toxin administration in transgenic mice leads to reduced gray matter blood flow as well as BBB breakdown. ${ }^{19}$ Pericyte degeneration in disease likely causes hypoperfusion as vessels lose their contractile ability; however, additional intrinsic differences in endothelial cells and pericytes between brain regions may also be involved.

The hippocampus is one of the first regions of the brain in which BBB leakage and breakdown occur in normal aging and pathologic findings are aggravated in patients with mild cognitive impairment. ${ }^{43}$ These findings may be attributable to the human hippocampus having fewer pericytes compared with other areas of the brain in addition to the presence of endothelial cells with a more inflammatory signature. ${ }^{9}$ Pericyte-deficient mice have reduced cerebral blood flow and BBB leakage in the hippocampus, albeit to a lesser extent than in the white matter. ${ }^{35,36}$ Nevertheless, hippocampal sensitivity to ischemic injury may occur due to underlying endothelial cell and pericyte differences in addition to reduced pericyte coverage. ${ }^{9}$ In healthy mice, blood flow and oxygenation levels in hippocampal vessels are lower than that in the cortex. ${ }^{103}$ Furthermore, hippocampal capillaries dilate to a lesser extent and frequency than cortical capillaries, possibly because of a longer and less contractile pericyte phenotype. Hippocampal mural cells also have lower expression of ion channels and skeletal muscle actin (Actal). In addition, hippocampal endothelial cells have reduced prostaglandin E synthase (Ptges) and Kir2.1, an inwardly rectifying potassium channel that propagates the vasodilatory signals from capillaries to arterioles. ${ }^{103}$ Therefore, the hippocampus appears to be 
particularly vulnerable to BBB disruption because of regional differences in pericyte morphologic mechanisms and neurovascular coupling, caused by regional heterogeneous endothelial cell and pericyte gene expression. This leads to reduced endothelial-pericyte communication, for example, via prostaglandin, ${ }^{103}$ thereby affecting their ability to control cerebral blood flow.

Endothelial cells are known to secrete vasoactive substances, such as endothelin (ET)-1, which bind to receptors on pericytes. ET-1 from endothelial cells elicits pericyte contraction via inositol phosphate pathways. ${ }^{13}$ Increased ET-1 levels in brain tissue have been found in vascular dementia. ${ }^{68}$ However, ET-1 levels in AD tissue in the literature differ, ${ }^{68,69}$ suggesting that other vasoactive substances, such as nitric oxide, are involved in control of cerebral blood flow, contributing to the hypoperfusion seen in dementia. ${ }^{61,71}$ Dysfunctional endothelial cells secrete less nitric oxide ${ }^{60}$ required for vasodilation via pericyte relaxation via cGMP-dependent pathways. ${ }^{104}$ In patients, functional single-nucleotide polymorphisms in NOS3, the gene encoding endothelial cell nitric oxide synthase, have different associations with SVD, with single-nucleotide polymorphisms leading to lower nitric oxide plasma levels, indicating a trend to higher SVD risk. ${ }^{67}$ In dementia, the regional difference in endothelial-pericyte gene expression, dysregulation of paracrine signaling via vasoconstrictive and vasodilatory substances, and a loss of pericytes coverage and number contribute to local reduction in brain perfusion $^{61,71}$ (Figure 2). Subsequently, a compensatory angiogenesis in response to hypoxia from hypoperfusion is thought to occur in dementia. ${ }^{25}$

\section{Endothelial-Pericyte Crosstalk in Angiogenesis}

Rodent studies indicate the importance of PDGF- $\beta$ / PDGFR- $\beta$ signaling in angiogenesis as well as the formation of the BBB in development, ${ }^{53,105}$ regulating numerous processes such as proliferation and migration. ${ }^{105}$ In development, endothelial cells express PDGF- $\beta$ at areas of angiogenesis, leading to proliferation of PDGFR$\beta$-expressing pericytes. ${ }^{105}$ This endothelial cell secretion of PDGF- $\beta$ is essential for recruitment of pericytes to sites of angiogenesis ${ }^{74}$ because knockout leads to up to a $90 \%$ reduction in pericyte number. ${ }^{106}$ The requirement of endothelial cell PDGF- $\beta$ for pericyte recruitment persists into adulthood. ${ }^{106}$ The chimeric nature of some knockout models indicates that endothelial cells that express PDGF- $\beta$ are unable to compensate for those without PDGF- $\beta,{ }^{106}$ demonstrating local paracrine endothelial cell PDGF- $\beta$ signaling to pericytes to ensure formation and maintenance of an adequately ensheathed capillary and functional BBB. ${ }^{35}$ Aberrant angiogenesis has been seen in regions of $\mathrm{AD}$ brain tissue ${ }^{26}$ possibly stimulated by hypoperfusion and subsequent hypoxia, secondary to dysfunction of endothelial-pericyte crosstalk described in the previous section. Angiogenic dysfunction is seen in $\mathrm{AD}$ and vascular dementia with increases in intrathecal angiogenic factors, such as transforming growth factor (TGF)- $\beta$ in patients, ${ }^{27}$ which is thought to be involved in initiating or promoting amyloidogenesis in $\mathrm{AD} .{ }^{107}$

Vascular endothelial growth factor (VEGF), another angiogenic factor, is also elevated in patients with $\mathrm{AD}$ and cSVD. $^{27}$ VEGF stimulates endothelial cell proliferation and is secreted by pericytes and endothelial cells. Pericytes require direct contact with endothelial cells to secrete VEGF via a pathway that also involves TGF- $\beta$, promoting endothelial cell survival and allowing vessel maturation by regulating prolieration. ${ }^{13,108,109}$ iPSC mural cells derived from patients with CADASIL have reduced VEGF secretion, leading to vessel destabilization, which can be rescued through VEGF supplementation. ${ }^{70}$ However, increased VEGF has been found in the white matter in patients with cSVD and AD without apparent rescue, suggesting that a more complex signaling mechanism is involved. ${ }^{24}$ Loss of pericytes leads to increased VEGF-A expression in endothelial cells, ${ }^{18}$ which may be a compensatory endothelial cell response to promote cell survival. However, it may also be attributable to loss of pericyte VEGF receptor 1, which regulates VEGF signaling by sequestration ${ }^{110}$ or a combination of both mechanisms. Endothelial overexpression of VEGF can be detrimental by antagonizing PDGF- $\beta$ through formation of VEGF receptor $2 /$ PDGFR- $\beta$ complexes in pericytes, suppressing PDGFR- $\beta$ signaling required for pericyte recruitment leading to immature leaky vessels as well as inappropriate endothelial cell hyperplasia..$^{13,110,111}$ VEGF is also known to increase paracellular permeability by reducing occludin protein expression. ${ }^{112}$ In summary, careful calibration of multiple molecular signals that are involved in both promotion and inhibition of endothelial cell proliferation, such as VEGF, is essential to ensure appropriate endothelial cell proliferation while limiting negative regulation of pericyte function.

Furthermore, these vessels may also form abnormally as seen in $P d g f b$ - and $P d g f r$-null mouse models. Despite having normal microvessel length and density, these mice have pathologic changes in areas with loss of pericyte coverage, ${ }^{18}$ for example, microhemorrhages, which are commonly seen in $\mathrm{cSVD}^{47}$ and $\mathrm{AD}^{48}$ Endothelial cells without pericyte contact have an altered shape with increased cytoplasmic thickness and luminal projections. ${ }^{18}$ The microvessels in the brains of mutant mice are dilated with up to a $25 \%$ increase in diameter compared with controls with areas of endothelial cell hyperplasia, ${ }^{18,74}$ which could be attributable to dysfunctional levels of VEGF. Therefore, disrupted pericyte signaling in AD and cSVD may cause secondary changes in endothelial cell morphologic mechanisms, proliferation, and tight junction expression, leading to subsequent $\mathrm{BBB}$ disruption (Figure 2). In recent years, the bidirectional relationship between endothelial cells and pericytes required for normal function has further been highlighted with the 
use of genetic sequencing to examine the downstream effects of loss of this communication.

\section{Endothelial-Pericyte Signaling Regulates Cellular Transcription}

The pericyte-deficient mouse models provide further insight into loss of BBB integrity in dementia through pericyte modulation of endothelial gene expression. Loss of pericyte coverage does not affect BBB-specific endothelial cell genes during development or in adults, indicating an intrinsic expression. ${ }^{37,66}$ However, reports of changes in endothelial cell junctional protein expression and localization differ among studies possibly because of increased loss with age. ${ }^{35,53,66}$ Despite these discrepancies in junctional protein expression levels, researchers who examined endothelial cell junctions saw structural abnormalities in junctional protein alignment in embryos ${ }^{53}$ or morphologic mechanisms with increased undulations of the endothelial membrane within these junctions in adult mice. ${ }^{66}$ Furthermore, the increase in junctional width between endothelial cells ${ }^{66}$ can be reversed in vitro with the addition of pericytes. ${ }^{53}$ Pericytes may not be directly involved in regulating BBBspecific gene transcription; however, in pericyteendothelial cell co-culture systems, pericytes increase the barrier strength up to fourfold when measured by transendothelial resistance. ${ }^{53}$ Therefore, the presence of pericytes and crosstalk with endothelial cells is required for the formation of a stronger, perhaps more functional BBB, with correct junctional protein alignment and morphologic features.

A possible explanation for the formation of a more robust $\mathrm{BBB}$ in the presence of pericytes was provided by a recent study by Mäe et al. ${ }^{37}$ Using adult pericytedeficient mice and sequencing of the endothelial cells, they found alterations in junctional complex alignment in areas of pericyte deficiency. Furthermore, as mentioned above, the endothelial cells retained their BBB-specific genes but had an overall shift in gene expression toward a venous pattern without pericyte contact. In areas of high BBB tracer leakage and pericyte loss, the endothelial cells had altered junctional protein complex distribution with increased expression of plasmalemma vesicle-associated protein (normally expressed in fenestrated capillaries, such as in the $\mathrm{ME}^{10}$ ) and low major facilitator superfamily domain containing 2a (MFSD2A) expression, which is involved in suppressing transcytosis, discussed below. Surprisingly, areas of BBB leakage had low expression of angiopoietin-2 (ANGPT2), ${ }^{37}$ suggesting an interesting role for this protein in maintaining BBB integrity.

ANGPT2 is involved in the angiopoietin/tyrosine protein kinase receptor TIE2 signaling pathway as an antagonist. TIE2 and ANGPT2 are expressed by endothelial cells. ${ }^{37,113}$ ANGPT2 is mainly reported for its autocrine role in blood vessel destabilization and pathologic angiogenesis through induction of pericyte loss, ${ }^{8,37,75}$ whereas pericytes are involved in paracrine regulation of the TIE2 signaling pathway, reducing vessel permeability in tumor, skin, and BBB models. ${ }^{114}$ Increased serum ANGPT2 levels have been found in APOE4 carrier patients with $\mathrm{AD}$ with white matter changes, ${ }^{39}$ and an overall generalized increase in endothelial cell Angpt2/ANGPT2 expression is seen in pericytedeficient mice, ${ }^{37}$ which fits with its involvement in blood vessel destabilization, leading to the BBB leakage in patients with $\mathrm{AD}$ and pericyte-deficient mice. In mice, ANGPT2 was expressed mainly in endothelial cells in pericyte-deficient areas of the brain, ${ }^{37,53}$ supporting the hypothesis that pericytes suppress endothelial cell expression of vessel destabilizing ANGPT2 and thereby maintaining BBB integrity. Therefore, it follows that high ANGPT2 expression is expected in areas of high BBB leakage because of its role in blood vessel destabilization. Surprisingly, Mäe et $\mathrm{al}^{37}$ found the opposite: low ANGPT2 expression in areas of high BBB leakage. Furthermore, endothelial cell-specific knockout of Angpt2 in pericytedeficient mice aggravated BBB leakage instead of the predicted rescue. To investigate this, they examined Angpt2 knockout mice (without pericyte deficiency) and found abnormal vessel morphologic mechanisms and abnormal CLDN-5 junctional protein staining. Similar abnormal vessel morphologic mechanisms and CLDN-5 distribution were also seen in the pericyte-deficient mice in areas of high leakage and low ANGPT2 expression. Together these data suggest that ANGPT2 exerts a protective effect in endothelial cells at the $\mathrm{BBB}$ by regulating junctional protein alignment required for maintenance of BBB integrity, which is particularly important in pericyte loss because Angpt2 knockout in pericyte-deficient mice worsens BBB leakage. ${ }^{37}$ This novel vessel stabilizing role for ANGPT2 may be context-dependent because a similar role has been seen in the lymphatic endothelium. ${ }^{115}$ ANGPT2-TIE2 signaling is involved in trafficking or stabilizing of junctional complexes, but further research is required into ANGPT2-TIE2 at the BBB. ${ }^{37}$ ANGPT2-TIE2 endothelial-pericyte interaction is complex and requires careful balancing to ensure maintenance of BBB integrity. More generalized changes in BBB permeability with pericyte deficiency have been seen through changes in transcytosis.

\section{Endothelial-Pericyte Signaling in Transcytosis and Increases in BBB Permeability}

In pericyte-deficient endothelial cells, transcytosis, movement of substances transcellularly in vesicles, is increased, ${ }^{18,53,66,82}$ suggesting pericyte regulation of endothelial cell transcytosis. Transcytosis occurs through the formation of caveolae, a form of nonspecific transport across the BBB. Caveolae increase with age in mice, 
leading to a shift from specific receptor-mediated transport to the nonspecific caveolae uptake. ${ }^{82}$ In particular, pericyte-free endothelial cells have reduced expression of the transferrin receptor (CD71) known to be involved in substrate-specific receptor-mediated transport. ${ }^{66}$ The shift from specific receptor-mediated transport to caveolar nonspecific transport that occurs with normal aging $^{82}$ is thought to occur earlier in dementia, leading to increased BBB permeability. ${ }^{63}$ The presence of inert tracer molecules within caveolae in BBB endothelial cells devoid of pericytes, ${ }^{53}$ suggest that increased BBB permeability occurs, in part, through increased transcytosis and not solely paracellularly through tight junction disruption as described above. In rodent models of large vessel stroke, an increase in endothelial caveolae number and size occured rapidly after stroke induction, coinciding with an initial increase in BBB permeability. ${ }^{64,65}$ A second phase of BBB leakage occurred 48 hours after stroke, which coincided with increased endothelial junctional gaps and tight junction redistribution. $^{64,65}$ Of interest, caveolin-1, a major caveolae component, colocalizes with CLDN-5 in vitro. ${ }^{72} \mathrm{How}-$ ever, caveolin-1 involvement in redistribution of CLDN-5 requires further study. ${ }^{65,72}$ Disruption to the BBB in dementia most likely occurs through a combination of increased transcytosis and disruption to paracellular junctions. One mechanism through which pericytes may be responsible for regulating transcytosis in endothelial cells of the BBB is via control of $M f_{s} d 2 a$ expression.

MFSD2A is highly expressed in brain endothelial cells compared to peripheral endothelial cells. ${ }^{116}$ MFSD2A is a protein involved in transcytosis suppression supported by data from $M f s d 2 a$ knockout mice that have normal vascular density and branching, tight junction organization, and pericyte coverage but increased endothelial cell transcytosis. ${ }^{116}$ MFSD2A expression is reduced at sites of BBB leakage and pericyte loss in rodent models. ${ }^{37}$ Reduced expression is seen only in endothelial cells that lack pericyte contact, implying direct paracrine signaling. Further supporting the importance of pericytes in maintaining healthy BBB function is the reduced expression of $M f s d 2 a / M F S D 2 A$ in normal aging accompanying reduced pericyte coverage. ${ }^{82}$ However, $M f s d 2 a$ suppression may not be solely responsible for the increase in BBB leakage seen in pericyte-deficient models. Contrary to data from Ben-Zvi et al, ${ }^{116}$ Mäe et al ${ }^{37}$ did not see any tracer leakage in $M f s d 2 a$ knockout mice. This discrepancy may be attributable to Ben-Zvi et $\mathrm{al}^{116}$ looking at tracer leakage in embryos and postnatal animals, whereas Mäe et $\mathrm{al}^{37}$ using adult animals in which there may be compensation through other mechanisms. Therefore, loss of endothelial-pericyte crosstalk contributes to $M f s d 2 a / M F S D 2 A$ suppression, which may have a role in increased BBB permeability through increased caveolar transcytosis as well as alterations in expression of other genes, such as those involved in neuroinflammation.

\section{Neuroinflammation and Endothelial-Pericyte Crosstalk}

The BBB plays an important role in limiting movement of inflammatory cells across the BBB into the brain, which is thought to be, in part, attributable to the brain's limited ability for regeneration of certain cell types, such as neurons. Disruption to the $\mathrm{BBB}$ and subsequent neuroinflammation are components of many neurodegenerative diseases, such as $\mathrm{AD}$ and $\mathrm{cSVD} .{ }^{89}$ Underlying sensitivity to $\mathrm{BBB}$ leakage of the hippocampus in $\mathrm{AD}^{43}$ may be related to higher endothelial cell expression of inflammatory genes in this brain region compared with cortical tissue. ${ }^{9}$ Leukocyte adhesion molecules vascular cell adhesion molecule 1 and intercellular adhesion molecule 1 are expressed on endothelial cells and responsible for leukocyte movement across the BBB. Increased levels of soluble vascular cell adhesion molecule 1 and intercellular adhesion molecule 1 are present in the serum of patients with CSVD and AD compared with age-matched controls $^{54,56}$ and associated with $\mathrm{A} \beta$ plaques in the brain. ${ }^{49}$ Increased intercellular adhesion molecule 1 is present in pericyte-devoid areas of vasculature in pericyte-deficient models, which is accompanied by brain parenchymal leukocyte infiltration. ${ }^{52}$ Increased expression of leukocyte adhesion molecules is also seen at sites of BBB leakage. ${ }^{37}$ Further supporting a role for pericytes in mediating endothelial leukocyte adhesion molecule expression are in vitro studies that showed that co-culture with pericytes is sufficient to reduce intercellular adhesion molecule 1 -positive endothelial cells. ${ }^{53}$ The clinical importance of controlling neuroinflammation is indicated by the correlation of increased soluble vascular cell adhesion molecule 1 levels in $\mathrm{AD}$ and $\mathrm{cSVD}$ with worsening cognitive impairment. $^{54,56}$ The exact mechanism through which pericytes regulate endothelial leukocyte adhesion molecule expression is not known; however, evidence suggests they play an important role.

Secretion of MMPs is an inflammatory mechanism that leads to BBB breakdown and pathologic findings. ${ }^{7}$ Under normal homeostatic conditions, MMPs from all cell types are required for remodeling of ECM necessary for processes such as angiogenesis or neurogenesis. ${ }^{7}$ However, in inflammation, MMPs are involved in breaking down components of the BBB and NVU, allowing ingress of inflammatory cells into the brain. ${ }^{117}$ In disease, MMPs are involved in BBB disruption through several mechanisms. Studies have found elevations in serum MMP9 and an association with higher WMH volumes in patients with cSVD. ${ }^{55}$ Furthermore, increased MMP9 staining occurs in leptomeningeal vessels of patients with $\mathrm{AD}$ and cerebral amyloid angiopathy from $A \beta$ deposition and 
concurrent intracerebral hemorrhage. ${ }^{49}$ Similar findings are seen in $P d g f r b$-null mice and a transgenic AD mouse model with increased MMP9 tissue protein levels. There is reduced collagen in these mice, indicating that MMP9 may be involved in the breakdown of the ECM collagen that contributes to $\mathrm{BBB}$ disruption and leakage. ${ }^{53,118}$

Another mechanism through which MMPs act to break down the BBB involves disruption of endothelial junctional proteins (Figure 2). A transgenic AD mouse model with increased MMP9 levels found reduced zonula occludens protein 1, occluding, and CLDN-5 protein levels in brain tissue lysate, indicating disruption to the endothelial cell junctions. The increase in MMP9 was mediated by CypA in pericytes. ${ }^{118}$ Blockage and/or pharmacologic treatment of MMP9 and CypA reversed BBB leakage, demonstrating that dysregulation of these pathways alone can be responsible for BBB disruption. ${ }^{38,118}$ Activation of the proinflammatory CypA-MMP9 cascade that leads to ingress of neurotoxic substances into the brain is APOE4 isoformspecific, ${ }^{118}$ and pericytes and endothelial cells of APOE4 carrier patients with AD have increased CypA and MMP9 protein levels. ${ }^{31}$ Clinical data indicate that $A P O E 4$ carrier patients with $\mathrm{AD}$ who have $\mathrm{BBB}$ leakage and increased pericyte damage also have increased CSF CypA and MMP9 levels. ${ }^{44}$

APOE4 isoform-specific CypA-MMP9 activation is thought to occur because APOE4 only weakly binds pericyte LRP1, whereas APOE3 binds LRP1 with high affinity, inhibiting the CypA-MMP9 cascade. $^{118}$ LRP1 is also important in endothelial cells. In a mouse model, loss of endothelial LRP1 led to CypA-MMP9 activation similar to that in the transgenic $\mathrm{AD}$ mouse discussed above, ${ }^{118}$ resulting in loss of tight junctions and subsequent $\mathrm{BBB}$ breakdown, neuronal death, and reduced cognitive function. This phenotype was rescued by reexpression of endothelial LRP1 or CypA inhibition. ${ }^{38}$ Reduced levels of LRP1 have been found in $\mathrm{AD}$ brain tissue, ${ }^{57}$ which, together with the increased CypA and MMP9 in CSF, ${ }^{44}$ demonstrate the involvement of this pathway in pathologic findings. Therefore, LRP1 expression and signaling in pericytes and endothelial cells is important in controlling spurious activation of the CypA-MMP9 cascade that leads to BBB breakdown and other features of dementia pathologic findings, such as $A \beta$ clearance. ${ }^{23}$

In addition to BBB breakdown, the activation of the proinflammatory CypA-MMP9 cascade may also be involved in $A \beta$ pathologic findings. The link between APOE4 and A $\beta$ occurs through the receptor for advanced glycation end products in brain capillaries. The receptor for advanced glycation end products is expressed on brain endothelial cells and is responsible for transport of $A \beta$ across the BBB into the brain. ${ }^{119}$ An increase in endothelial receptor for advanced glycation end products has been seen in $\mathrm{AD}$ brain tissue $\mathrm{e}^{57,58}$ and together with loss of LRP1, ${ }^{57}$ which traffics $A \beta$ out of the brain, leads to $A \beta$ accumulation seen in $\mathrm{AD} .{ }^{57}$ Inhibition of CypA by cyclosporine reduces $A \beta$ accumulation in APOE4-induced mural cells. ${ }^{51}$ However, the relationship is likely more complex, with a previous study ${ }^{120}$ finding no effect of CypA inhibition on $\mathrm{A} \beta$ pathologic findings in an APOE4 mouse model but an involvement in improved BBB integrity, prevention of neuronal loss, and behavioral deficits. Overall, inhibition of CypA appears to improve BBB integrity and reduce neuronal loss and behavioral deficits in several rodent models. ${ }^{38,120}$ In summary, neuroinflammation contributes to pathologic findings of dementia through increased leukocyte trafficking into the brain, CypA-MMP9 disruption to the ECM and tight junctions, and possible increased $A \beta$ accumulation in the brain, leading to BBB breakdown through abnormal pericyte-endothelial cell-mediated signaling.

\section{Conclusion}

The brain environment is delicate and requires careful balance of homeostatic pathways. The BBB is important in maintaining this balance by controlling interactions with the systemic circulation. Disruption to the BBB can lead to pathologic findings and can be the cause or consequence of disease. This review described how endothelial cells and pericytes perform a vital role in maintaining the BBB through intricate crosstalk and how this is altered in both cSVD and AD. It highlighted the overlap of pathologic findings between these two major forms of dementia by focusing on the many ways in which disturbance of pericyte-endothelial cell communication undermines the BBB. There is still much to be understood about endothelial-pericyte crosstalk and many pathways yet to be elucidated. However, understanding the careful signaling and its dysregulation in dementia will allow for the development of future therapies to help with what has become one of the most important diseases in the aging population-dementia.

\section{References}

1. Wardlaw J, Smith C, Dichgans M: Small vessel disease: mechanisms and clinical implications. Lancet Neurol 2019, 18:684-696

2. Dichgans M, Zietemann V: Prevention of vascular cognitive impairment. Stroke 2012, 43:3137-3146

3. Liu Y, Braidy N, Poljak A, Chan DKY, Sachdev P: Cerebral small vessel disease and the risk of Alzheimer's disease: a systematic review. Ageing Res Rev 2018, 47:41-48

4. Zlokovic BV: Neurovascular pathways to neurodegeneration in Alzheimer's disease and other disorders. Nat Rev Neurosci 2011, 12: 723-738

5. Pantoni L: Cerebral small vessel disease: from pathogenesis and clinical characteristics to therapeutic challenges. Lancet Neurol 2010, 9:689-701

6. Abbott NJ, Patabendige AA, Dolman DE, Yusof SR, Begley DJ: Structure and function of the blood-brain barrier. Neurobiol Dis 2010, 37:13-25 
7. Rosenberg GA: Neurological diseases in relation to the blood-brain barrier. J Cereb Blood Flow Metab 2012, 32:1139-1151

8. Armulik A, Abramsson A, Betsholtz C: Endothelial/pericyte interactions. Circ Res 2005, 97:512-523

9. Yang AC, Vest RT, Kern F, Lee D, Maat CA, Losada PM, Chen MB, Agam M, Schaum N, Khoury N, Calcuttawala K, Palovics R, Shin A, Wang EY, Luo J, Gate D, Siegenthaler JA, McNerney MW, Keller A, Wyss-Coray T: A human brain vascular atlas reveals diverse cell mediators of Alzheimer's disease risk. bioRxiv 2021. [Preprint] doi: 10.1101/2021.04.26.441262

10. Pfau SJ, Langen UH, Fisher TM, Prakash I, Nagpurwala F, Lozoya RA, Lee W-CA, Wu Z, Gu C: Vascular and perivascular cell profiling reveals the molecular and cellular bases of bloodbrain barrier heterogeneity. bioRxiv 2021. [Preprint] doi:10. 1101/2021.04.26.441465

11. Grant R, Hartmann D, Underly R, Berthiaume A, Bhat N, Shih A: Organizational hierarchy and structural diversity of microvascular pericytes in adult mouse cortex. J Cereb Blood Flow Metab 2019, 39: 411-425

12. Vanlandewijck M, He L, Mäe MA, Andrae J, Ando K, Del Gaudio F, Nahar K, Lebouvier T, Laviña B, Gouveia L, Sun Y, Raschperger E, Räsänen M, Zarb Y, Mochizuki N, Keller A, Lendahl U, Betsholtz C: A molecular atlas of cell types and zonation in the brain vasculature. Nature 2018, 554:475-480

13. Rucker H, Wynder HJ, Thomas W: Cellular mechanisms of CNS pericytes. Brain Res Bull 2000, 51:363-369

14. Morita K, Sasaki H, Furuse M, Tsukita S: Endothelial claudin: claudin-5/TMVCF constitutes tight junction strands in endothelial cells. J Cell Biol 1999, 147:185-194

15. Stamatovic SM, Johnson AM, Keep RF, Andjelkovic AV: Junctional proteins of the blood-brain barrier: new insights into function and dysfunction. Tissue Barriers 2016, 4:e1154641

16. Nitta T, Hata M, Gotoh S, Seo Y, Sasaki H, Hashimoto N, Furuse M, Tsukita S: Size-selective loosening of the blood-brain barrier in claudin-5-deficient mice. J Cell Biol 2003, 161:653-660

17. Bauer H, Bauer H, Lametschwandtner A, Amberger A, Ruiz P, Steiner M: Neovascularization and the appearance of morphological characteristics of the blood-brain barrier in the embryonic mouse central nervous system. Brain Res Dev Brain Res 1993, 75: 269-278

18. Hellström M, Gerhardt H, Kalén M, Li X, Eriksson U, Wolburg H, Betsholtz C: Lack of pericytes leads to endothelial hyperplasia and abnormal vascular morphogenesis. J Cell Biol 2001, 153:543-553

19. Nikolakopoulou AM, Montagne A, Kisler K, Dai Z, Wang Y, Huuskonen MT, Sagare AP, Lazic D, Sweeney MD, Kong P, Wang M, Owens NC, Lawson EJ, Xie X, Zhao Z, Zlokovic BV: Pericyte loss leads to circulatory failure and pleiotrophin depletion causing neuron loss. Nat Neurosci 2019, 22:1089-1098

20. Sweeney MD, Kisler K, Montagne A, Toga AW, Zlokovic BV: The role of brain vasculature in neurodegenerative disorders. Nat Neurosci 2018, 21:1318-1331

21. Nelson AR, Sweeney MD, Sagare AP, Zlokovic BV: Neurovascular dysfunction and neurodegeneration in dementia and Alzheimer's disease. Biochim Biophys Acta 2016, 1862:887-900

22. Thal D, Ghebremedhin E, Orantes M, Wiestler O: Vascular pathology in Alzheimer disease: correlation of cerebral amyloid angiopathy and arteriosclerosis/lipohyalinosis with cognitive decline. J Neuropathol Exp Neurol 2003, 62:1287-1301

23. Sagare AP, Bell RD, Zhao Z, Ma Q, Winkler EA, Ramanathan A, Zlokovic BV: Pericyte loss influences Alzheimer-like neurodegeneration in mice. Nat Commun 2013, 4:2932

24. Tayler H, Miners JS, Güzel Ö, MacLachlan R, Love S: Mediators of cerebral hypoperfusion and blood-brain barrier leakiness in Alzheimer's disease, vascular dementia and mixed dementia. Brain Pathol 2021, 31:e12935

25. Vagnucci AH Jr, Li WW: Alzheimer's disease and angiogenesis. Lancet 2003, 361:605-608
26. Desai BS, Schneider JA, Li JL, Carvey PM, Hendey B: Evidence of angiogenic vessels in Alzheimer's disease. J Neural Transm 2009, 116:587-597

27. Tarkowski E, Issa $\mathrm{R}$, Sjögren $\mathrm{M}$, Wallin A, Blennow $\mathrm{K}$, Tarkowski A, Kumar P: Increased intrathecal levels of the angiogenic factors VEGF and TGF-beta in Alzheimer's disease and vascular dementia. Neurobiol Aging 2002, 23:237-243

28. McAleese KE, Graham S, Dey M, Walker L, Erskine D, Johnson M, Johnston E, Thomas AJ, McKeith IG, DeCarli C, Attems J: Extravascular fibrinogen in the white matter of Alzheimer's disease and normal aged brains: implications for fibrinogen as a biomarker for Alzheimer's disease. Brain Pathol 2019, 29:414-424

29. Rajani RM, Ratelade J, Domenga-Denier V, Hase Y, Kalimo H, Kalaria RN, Joutel A: Blood brain barrier leakage is not a consistent feature of white matter lesions in CADASIL. Acta Neuropathol Commun 2019, 7:187

30. Grinberg L, Thal D: Vascular pathology in the aged human brain. Acta Neuropathol 2010, 119:277-290

31. Halliday MR, Rege SV, Ma Q, Zhao Z, Miller CA, Winkler EA, Zlokovic BV: Accelerated pericyte degeneration and blood-brain barrier breakdown in apolipoprotein E4 carriers with Alzheimer's disease. J Cereb Blood Flow Metab 2016, 36:216-227

32. Sengillo JD, Winkler EA, Walker CT, Sullivan JS, Johnson M, Zlokovic BV: Deficiency in mural vascular cells coincides with blood-brain barrier disruption in Alzheimer's disease. Brain Pathol 2013, 23:303-310

33. Sironi L, Guerrini U, Tremoli E, Miller I, Gelosa P, Lascialfari A, Zucca I, Eberini I, Gemeiner M, Paoletti R, Gianazza E: Analysis of pathological events at the onset of brain damage in stroke-prone rats: a proteomics and magnetic resonance imaging approach. J Neurosci Res 2004, 78:115-122

34. Schreiber S, Bueche CZ, Garz C, Kropf S, Angenstein F, Goldschmidt J, Neumann J, Heinze HJ, Goertler M, Reymann KG, Braun $\mathrm{H}$ : The pathologic cascade of cerebrovascular lesions in SHRSP: is erythrocyte accumulation an early phase? J Cereb Blood Flow Metab 2012, 32:278-290

35. Bell RD, Winkler EA, Sagare AP, Singh I, LaRue B, Deane R, Zlokovic BV: Pericytes control key neurovascular functions and neuronal phenotype in the adult brain and during brain aging. Neuron 2010, 68:409-427

36. Montagne A, Nikolakopoulou AM, Zhao Z, Sagare AP, Si G, Lazic D, Barnes SR, Daianu M, Ramanathan A, Go A, Lawson EJ, Wang Y, Mack WJ, Thompson PM, Schneider JA, Varkey J, Langen R, Mullins E, Jacobs RE, Zlokovic BV: Pericyte degeneration causes white matter dysfunction in the mouse central nervous system. Nat Med 2018, 24:326-337

37. Mäe MA, He L, Nordling S, Vazquez-Liebanas E, Nahar K, Jung B, Li X, Tan BC, Chin Foo J, Cazenave-Gassiot A, Wenk MR, Zarb Y, Lavina B, Quaggin SE, Jeansson M, Gu C, Silver DL, Vanlandewijck M, Butcher EC, Keller A, Betsholtz C: Single-cell analysis of blood-brain barrier response to pericyte loss. Circ Res 2021, 128:e46-e62

38. Nikolakopoulou AM, Wang Y, Ma Q, Sagare AP, Montagne A, Huuskonen MT, Rege SV, Kisler K, Dai Z, Körbelin J, Herz J, Zhao Z, Zlokovic BV: Endothelial LRP1 protects against neurodegeneration by blocking cyclophilin A. J Exp Med 2021, 218: e20202207

39. Raman MR, Himali JJ, Conner SC, DeCarli C, Vasan RS, Beiser AS, Seshadri S, Maillard P, Satizabal CL: Circulating vascular growth factors and magnetic resonance imaging markers of small vessel disease and atrophy in middle-aged adults. Stroke 2018, 49: $2227-2229$

40. Wardlaw JM, Makin SJ, Valdés Hernández MC, Armitage PA, Heye AK, Chappell FM, Muñoz-Maniega S, Sakka E, Shuler K, Dennis MS, Thrippleton MJ: Blood-brain barrier failure as a core mechanism in cerebral small vessel disease and dementia: evidence from a cohort study. Alzheimers Dement 2017, 13:634-643 
41. Zhang CE, Wong SM, Uiterwijk R, Backes WH, Jansen JFA, Jeukens C, van Oostenbrugge RJ, Staals J: Blood-brain barrier leakage in relation to white matter hyperintensity volume and cognition in small vessel disease and normal aging. Brain Imaging Behav 2019, 13:389-395

42. van de Haar HJ, Jansen JFA, van Osch MJP, van Buchem MA, Muller M, Wong SM, Hofman PAM, Burgmans S, Verhey FRJ, Backes WH: Neurovascular unit impairment in early Alzheimer's disease measured with magnetic resonance imaging. Neurobiol Aging 2016, 45:190-196

43. Montagne A, Barnes SR, Sweeney MD, Halliday MR, Sagare AP, Zhao Z, Toga AW, Jacobs RE, Liu CY, Amezcua L, Harrington MG, Chui HC, Law M, Zlokovic BV: Blood-brain barrier breakdown in the aging human hippocampus. Neuron 2015, 85:296-302

44. Montagne A, Nation DA, Sagare AP, Barisano G, Sweeney MD, Chakhoyan A, Pachicano M, Joe E, Nelson AR, D'Orazio LM, Buennagel DP, Harrington MG, Benzinger TLS, Fagan AM, Ringman JM, Schneider LS, Morris JC, Reiman EM, Caselli RJ, Chui HC, Tcw J, Chen Y, Pa J, Conti PS, Law M, Toga AW, Zlokovic BV: APOE4 leads to blood-brain barrier dysfunction predicting cognitive decline. Nature 2020, 581:71-76

45. Schreiber S, Bueche CZ, Garz C, Braun H: Blood brain barrier breakdown as the starting point of cerebral small vessel disease?: new insights from a rat model. Exp Transl Stroke Med 2013, 5:4

46. Toledo JB, Arnold SE, Raible K, Brettschneider J, Xie SX, Grossman M, Monsell SE, Kukull WA, Trojanowski JQ: Contribution of cerebrovascular disease in autopsy confirmed neurodegenerative disease cases in the National Alzheimer's Coordinating Centre. Brain 2013, 136:2697-2706

47. Patel B, Lawrence AJ, Chung AW, Rich P, Mackinnon AD, Morris RG, Barrick TR, Markus HS: Cerebral microbleeds and cognition in patients with symptomatic small vessel disease. Stroke 2013, 44:356-361

48. Cordonnier C, van der Flier WM: Brain microbleeds and Alzheimer's disease: innocent observation or key player? Brain 2011, 134: 335-344

49. Verbeek MM, Otte-Höller I, Westphal JR, Wesseling P, Ruiter DJ, de Waal RM: Accumulation of intercellular adhesion molecule-1 in senile plaques in brain tissue of patients with Alzheimer's disease. Am J Pathol 1994, 144:104-116

50. Bailey EL, McBride MW, Beattie W, McClure JD, Graham D, Dominiczak AF, Sudlow CL, Smith C, Wardlaw JM: Differential gene expression in multiple neurological, inflammatory and connective tissue pathways in a spontaneous model of human small vessel stroke. Neuropathol Appl Neurobiol 2014, 40:855-872

51. Blanchard JW, Bula M, Davila-Velderrain J, Akay LA, Zhu L, Frank A, Victor MB, Bonner JM, Mathys H, Lin YT, Ko T, Bennett DA, Cam HP, Kellis M, Tsai LH: Reconstruction of the human blood-brain barrier in vitro reveals a pathogenic mechanism of APOE4 in pericytes. Nat Med 2020, 26:952-963

52. Török O, Schreiner B, Schaffenrath J, Tsai HC, Maheshwari U, Stifter SA, Welsh C, Amorim A, Sridhar S, Utz SG, Mildenberger W, Nassiri S, Delorenzi M, Aguzzi A, Han MH, Greter M, Becher B, Keller A: Pericytes regulate vascular immune homeostasis in the CNS. Proc Natl Acad Sci U S A 2021, 118. e2016587118

53. Daneman R, Zhou L, Kebede AA, Barres BA: Pericytes are required for blood-brain barrier integrity during embryogenesis. Nature 2010, 468:562-566

54. Rouhl RP, Damoiseaux JG, Lodder J, Theunissen RO, Knottnerus IL, Staals J, Henskens LH, Kroon AA, de Leeuw PW, Tervaert JW, van Oostenbrugge RJ: Vascular inflammation in cerebral small vessel disease. Neurobiol Aging 2012, 33:1800-1806

55. Kim Y, Kim YK, Kim NK, Kim SH, Kim OJ, Oh SH: Circulating matrix metalloproteinase-9 level is associated with cerebral white matter hyperintensities in non-stroke individuals. Eur Neurol 2014, $72: 234-240$
56. Huang CW, Tsai MH, Chen NC, Chen WH, Lu YT, Lui CC, Chang YT, Chang WN, Chang AY, Chang CC: Clinical significance of circulating vascular cell adhesion molecule-1 to white matter disintegrity in Alzheimer's dementia. Thromb Haemost 2015, 114: $1230-1240$

57. Donahue JE, Flaherty SL, Johanson CE, Duncan JA, Silverberg GD, Miller MC, Tavares R, Yang W, Wu Q, Sabo E, Hovanesian V, Stopa EG: RAGE, LRP-1, and amyloid-beta protein in Alzheimer's disease. Acta Neuropathol 2006, 112:405-415

58. Miller MC, Tavares R, Johanson CE, Hovanesian V, Donahue JE, Gonzalez L, Silverberg GD, Stopa EG: Hippocampal RAGE immunoreactivity in early and advanced Alzheimer's disease. Brain Res 2008, 1230:273-280

59. Ihara M, Polvikoski TM, Hall R, Slade JY, Perry RH, Oakley AE, Englund E, O'Brien JT, Ince PG, Kalaria RN: Quantification of myelin loss in frontal lobe white matter in vascular dementia, Alzheimer's disease, and dementia with Lewy bodies. Acta Neuropathol 2010, 119:579-589

60. Rajani RM, Quick S, Ruigrok SR, Graham D, Harris SE, Verhaaren BFJ, Fornage M, Seshadri S, Atanur SS, Dominiczak AF, Smith C, Wardlaw JM, Williams A: Reversal of endothelial dysfunction reduces white matter vulnerability in cerebral small vessel disease in rats. Sci Transl Med 2018, 10: eaam9507

61. Shi Y, Thrippleton MJ, Makin SD, Marshall I, Geerlings MI, de Craen AJM, van Buchem MA, Wardlaw JM: Cerebral blood flow in small vessel disease: a systematic review and meta-analysis. J Cereb Blood Flow Metab 2016, 36:1653-1667

62. Wardlaw JM, Sandercock PA, Dennis MS, Starr J: Is breakdown of the blood-brain barrier responsible for lacunar stroke, leukoaraiosis, and dementia? Stroke 2003, 34:806-812

63. Rasmussen IJ, Tybjærg-Hansen A, Rasmussen KL, Nordestgaard BG, Frikke-Schmidt R: Blood-brain barrier transcytosis genes, risk of dementia and stroke: a prospective cohort study of 74,754 individuals. Eur J Epidemiol 2019, 34:579-590

64. Nahirney PC, Reeson P, Brown CE: Ultrastructural analysis of bloodbrain barrier breakdown in the peri-infarct zone in young adult and aged mice. J Cereb Blood Flow Metab 2016, 36:413-425

65. Knowland D, Arac A, Sekiguchi KJ, Hsu M, Lutz SE, Perrino J, Steinberg GK, Barres BA, Nimmerjahn A, Agalliu D: Stepwise recruitment of transcellular and paracellular pathways underlies blood-brain barrier breakdown in stroke. Neuron 2014, 82:603-617

66. Armulik A, Genové G, Mäe M, Nisancioglu MH, Wallgard E, Niaudet C, He L, Norlin J, Lindblom P, Strittmatter K, Johansson BR, Betsholtz C: Pericytes regulate the blood-brain barrier. Nature 2010, 468:557-561

67. Hassan A, Gormley K, O'Sullivan M, Knight J, Sham P, Vallance P, Bamford J, Markus H: Endothelial nitric oxide gene haplotypes and risk of cerebral small-vessel disease. Stroke 2004, 35:654-659

68. Barker R, Ashby EL, Wellington D, Barrow VM, Palmer JC, Kehoe PG, Esiri MM, Love S: Pathophysiology of white matter perfusion in Alzheimer's disease and vascular dementia. Brain 2014, 137:1524-1532

69. Luo J, Grammas P: Endothelin-1 is elevated in Alzheimer's disease brain microvessels and is neuroprotective. J Alzheimers Dis 2010, 21: 887-896

70. Kelleher J, Dickinson A, Cain S, Hu Y, Bates N, Harvey A, Ren J, Zhang W, Moreton FC, Muir KW, Ward C, Touyz RM, Sharma P, Xu Q, Kimber SJ, Wang T: Patient-specific iPSC model of a genetic vascular dementia syndrome reveals failure of mural cells to stabilize capillary structures. Stem Cell Rep 2019, 13:817-831

71. Ruitenberg A, den Heijer $\mathrm{T}$, Bakker SL, van Swieten JC, Koudstaal PJ, Hofman A, Breteler MM: Cerebral hypoperfusion and clinical onset of dementia: the Rotterdam study. Ann Neurol 2005, 57:789-794

72. Liu J, Jin X, Liu KJ, Liu W: Matrix metalloproteinase-2-mediated occludin degradation and caveolin-1-mediated claudin-5 
redistribution contribute to blood-brain barrier damage in early ischemic stroke stage. J Neurosci 2012, 32:3044-3057

73. Bailey EL, Wardlaw JM, Graham D, Dominiczak AF, Sudlow CL, Smith C: Cerebral small vessel endothelial structural changes predate hypertension in stroke-prone spontaneously hypertensive rats: a blinded, controlled immunohistochemical study of 5- to 21-week-old rats. Neuropathol Appl Neurobiol 2011, 37:711-726

74. Lindahl P, Johansson BR, Levéen P, Betsholtz C: Pericyte loss and microaneurysm formation in PDGF-B-deficient mice. Science 1997, 277:242-245

75. Maisonpierre PC, Suri C, Jones PF, Bartunkova S, Wiegand SJ, Radziejewski C, Compton D, McClain J, Aldrich TH, Papadopoulos N, Daly TJ, Davis S, Sato TN, Yancopoulos GD: Angiopoietin-2, a natural antagonist for Tie2 that disrupts in vivo angiogenesis. Science 1997, 277:55-60

76. Wardlaw JM, Smith EE, Biessels GJ, Cordonnier C, Fazekas F, Frayne R, et al: Neuroimaging standards for research into small vessel disease and its contribution to ageing and neurodegeneration. Lancet Neurol 2013, 12:822-838

77. Lee S, Viqar F, Zimmerman ME, Narkhede A, Tosto G, Benzinger TL, Marcus DS, Fagan AM, Goate A, Fox NC, Cairns NJ, Holtzman DM, Buckles V, Ghetti B, McDade E, Martins RN, Saykin AJ, Masters CL, Ringman JM, Ryan NS, Förster S, Laske C, Schofield PR, Sperling RA, Salloway S, Correia S, Jack C Jr, Weiner M, Bateman RJ, Morris JC, Mayeux R, Brickman AM: White matter hyperintensities are a core feature of Alzheimer's disease: evidence from the dominantly inherited Alzheimer network. Ann Neurol 2016, 79:929-939

78. Debette S, Markus HS: The clinical importance of white matter hyperintensities on brain magnetic resonance imaging: systematic review and meta-analysis. BMJ 2010, 341:c3666

79. Winkler EA, Sengillo JD, Bell RD, Wang J, Zlokovic BV: Bloodspinal cord barrier pericyte reductions contribute to increased capillary permeability. J Cereb Blood Flow Metab 2012, 32:1841-1852

80. Frank RN, Turczyn TJ, Das A: Pericyte coverage of retinal and cerebral capillaries. Invest Ophthalmol Vis Sci 1990, 31:999-1007

81. Armulik A, Genové G, Betsholtz C: Pericytes: developmental, physiological, and pathological perspectives, problems, and promises. Dev Cell 2011, 21:193-215

82. Yang AC, Stevens MY, Chen MB, Lee DP, Stähli D, Gate D, Contrepois K, Chen W, Iram T, Zhang L, Vest RT, Chaney A, Lehallier B, Olsson N, du Bois H, Hsieh R, Cropper HC, Berdnik D, Li L, Wang EY, Traber GM, Bertozzi CR, Luo J, Snyder MP, Elias JE, Quake SR, James ML, Wyss-Coray T: Physiological bloodbrain transport is impaired with age by a shift in transcytosis. Nature 2020, 583:425-430

83. Paik JH, Skoura A, Chae SS, Cowan AE, Han DK, Proia RL, Hla T: Sphingosine 1-phosphate receptor regulation of N-cadherin mediates vascular stabilization. Genes Dev 2004, 18:2392-2403

84. Allende ML, Yamashita T, Proia RL: G-protein-coupled receptor S1P1 acts within endothelial cells to regulate vascular maturation. Blood 2003, 102:3665-3667

85. Ceccom J, Loukh N, Lauwers-Cances V, Touriol C, Nicaise Y, Gentil C, Uro-Coste E, Pitson S, Maurage CA, Duyckaerts C, Cuvillier O, Delisle MB: Reduced sphingosine kinase-1 and enhanced sphingosine 1-phosphate lyase expression demonstrate deregulated sphingosine 1-phosphate signaling in Alzheimer's disease. Acta Neuropathol Commun 2014, 2:12

86. Asle-Rousta M, Kolahdooz Z, Dargahi L, Ahmadiani A, Nasoohi S: Prominence of central sphingosine-1-phosphate receptor-1 in attenuating a $\beta$-induced injury by fingolimod. J Mol Neurosci 2014, 54: 698-703

87. Malaplate-Armand C, Florent-Béchard S, Youssef I, Koziel V, Sponne I, Kriem B, Leininger-Muller B, Olivier JL, Oster T, Pillot T: Soluble oligomers of amyloid-beta peptide induce neuronal apoptosis by activating a cPLA2-dependent sphingomyelinase-ceramide pathway. Neurobiol Dis 2006, 23:178-189
88. Chua XY, Chai YL, Chew WS, Chong JR, Ang HL, Xiang P, Camara K, Howell AR, Torta F, Wenk MR, Hilal S, Venketasubramanian N, Chen CP, Herr DR, Lai MKP: Immunomodulatory sphingosine-1-phosphates as plasma biomarkers of Alzheimer's disease and vascular cognitive impairment. Alzheimers Res Ther 2020, 12:122

89. Fu Y, Yan Y: Emerging role of immunity in cerebral small vessel disease. Front Immunol 2018, 9:67

90. Scheppke L, Murphy EA, Zarpellon A, Hofmann JJ, Merkulova A, Shields DJ, Weis SM, Byzova TV, Ruggeri ZM, Iruela-Arispe ML, Cheresh DA: Notch promotes vascular maturation by inducing integrin-mediated smooth muscle cell adhesion to the endothelial basement membrane. Blood 2012, 119:2149-2158

91. Daneman R, Zhou L, Agalliu D, Cahoy JD, Kaushal A, Barres BA: The mouse blood-brain barrier transcriptome: a new resource for understanding the development and function of brain endothelial cells. PLoS One 2010, 5:e13741

92. Winkler EA, Bell RD, Zlokovic BV: Pericyte-specific expression of PDGF beta receptor in mouse models with normal and deficient PDGF beta receptor signaling. Mol Neurodegener 2010, 5:32

93. Shen J, Ishii $Y, X u$ G, Dang TC, Hamashima T, Matsushima T, Yamamoto S, Hattori Y, Takatsuru Y, Nabekura J, Sasahara M: PDGFR- $\beta$ as a positive regulator of tissue repair in a mouse model of focal cerebral ischemia. J Cereb Blood Flow Metab 2012, 32: 353-367

94. Muoio V, Persson PB, Sendeski MM: The neurovascular unit concept review. Acta Physiol 2014, 210:790-798

95. Hall CN, Reynell C, Gesslein B, Hamilton NB, Mishra A, Sutherland BA, O'Farrell FM, Buchan AM, Lauritzen M, Attwell D: Capillary pericytes regulate cerebral blood flow in health and disease. Nature 2014, 508:55-60

96. Hill RA, Tong L, Yuan P, Murikinati S, Gupta S, Grutzendler J: Regional blood flow in the normal and ischemic brain is controlled by arteriolar smooth muscle cell contractility and not by capillary pericytes. Neuron 2015, 87:95-110

97. Kisler K, Nelson AR, Rege SV, Ramanathan A, Wang Y, Ahuja A, Lazic D, Tsai PS, Zhao Z, Zhou Y, Boas DA, Sakadžić S, Zlokovic BV: Pericyte degeneration leads to neurovascular uncoupling and limits oxygen supply to brain. Nat Neurosci 2017, 20: 406-416

98. Alarcon-Martinez L, Yilmaz-Ozcan S, Yemisci M, Schallek J, Kılıç K, Can A, Di Polo A, Dalkara T: Capillary pericytes express $\alpha$ smooth muscle actin, which requires prevention of filamentous-actin depolymerization for detection. Elife 2018, 7:e34861

99. Kim SJ, Kim SA, Choi YA, Park DY, Lee J: Alpha-smooth muscle actin-positive perivascular cells in diabetic retina and choroid. Int J Mol Sci 2020, 21:2158

100. Zhang W, Davis CM, Zeppenfeld DM, Golgotiu K, Wang MX, Haveliwala M, Hong D, Li Y, Wang RK, Iliff JJ, Alkayed NJ: Role of endothelium-pericyte signaling in capillary blood flow response to neuronal activity. J Cereb Blood Flow Metab 2021, 41:1873-1885

101. Hartmann DA, Berthiaume AA, Grant RI, Harrill SA, Koski T, Tieu T, McDowell KP, Faino AV, Kelly AL, Shih AY: Brain capillary pericytes exert a substantial but slow influence on blood flow. Nat Neurosci 2021, 24:633-645

102. Gonzales AL, Klug NR, Moshkforoush A, Lee JC, Lee FK, Shui B, Tsoukias NM, Kotlikoff MI, Hill-Eubanks D, Nelson MT: Contractile pericytes determine the direction of blood flow at capillary junctions. Proc Natl Acad Sci U S A 2020, 117:27022-27033

103. Shaw K, Bell L, Boyd K, Grijseels DM, Clarke D, Bonnar O, Crombag HS, Hall CN: Neurovascular coupling and oxygenation are decreased in hippocampus compared to neocortex because of microvascular differences. Nat Commun 2021, 12:3190

104. Haefliger IO, Zschauer A, Anderson DR: Relaxation of retinal pericyte contractile tone through the nitric oxide-cyclic guanosine monophosphate pathway. Invest Ophthalmol Vis Sci 1994, 35: 991-997 
105. Hellström M, Kalén M, Lindahl P, Abramsson A, Betsholtz C: Role of PDGF-B and PDGFR-beta in recruitment of vascular smooth muscle cells and pericytes during embryonic blood vessel formation in the mouse. Development 1999, 126:3047-3055

106. Bjarnegård M, Enge M, Norlin J, Gustafsdottir S, Fredriksson S, Abramsson A, Takemoto M, Gustafsson E, Fässler R, Betsholtz C: Endothelium-specific ablation of PDGFB leads to pericyte loss and glomerular, cardiac and placental abnormalities. Development 2004, 131:1847-1857

107. Wyss-Coray T, Masliah E, Mallory M, McConlogue L, JohnsonWood K, Lin C, Mucke L: Amyloidogenic role of cytokine TGFbeta1 in transgenic mice and in Alzheimer's disease. Nature 1997, 389:603-606

108. Franco M, Roswall P, Cortez E, Hanahan D, Pietras K: Pericytes promote endothelial cell survival through induction of autocrine VEGF-A signaling and Bcl-w expression. Blood 2011, 118: 2906-2917

109. Darland DC, Massingham LJ, Smith SR, Piek E, Saint-Geniez M, D'Amore PA: Pericyte production of cell-associated VEGF is differentiation-dependent and is associated with endothelial survival. Dev Biol 2003, 264:275-288

110. Eilken HM, Diéguez-Hurtado R, Schmidt I, Nakayama M, Jeong HW, Arf H, Adams S, Ferrara N, Adams RH: Pericytes regulate VEGF-induced endothelial sprouting through VEGFR1. Nat Commun 2017, 8:1574

111. Greenberg JI, Shields DJ, Barillas SG, Acevedo LM, Murphy E, Huang J, Scheppke L, Stockmann C, Johnson RS, Angle N, Cheresh DA: A role for VEGF as a negative regulator of pericyte function and vessel maturation. Nature 2008, 456:809-813

112. Wang W, Dentler WL, Borchardt RT: VEGF increases BMEC monolayer permeability by affecting occludin expression and tight junction assembly. Am J Physiol Heart Circ Physiol 2001, 280: $\mathrm{H} 434-\mathrm{H} 440$

113. Sundberg C, Kowanetz M, Brown LF, Detmar M, Dvorak HF: Stable expression of angiopoietin- 1 and other markers by cultured pericytes: phenotypic similarityes to a subpopulation of cells in maturing vessels during later stages of angiogenesis in vivo. Lab Invest 2002, 82 387-401

114. Geevarghese A, Herman IM: Pericyte-endothelial crosstalk: implications and opportunities for advanced cellular therapies. Transl Res 2014, 163:296-306

115. Souma T, Thomson BR, Heinen S, Carota IA, Yamaguchi S, Onay T, Liu P, Ghosh AK, Li C, Eremina V, Hong YK, Economides AN, Vestweber D, Peters KG, Jin J, Quaggin SE: Context-dependent functions of angiopoietin 2 are determined by the endothelial phosphatase VEPTP. Proc Natl Acad Sci U S A 2018, 115: $1298-1303$

116. Ben-Zvi A, Lacoste B, Kur E, Andreone BJ, Mayshar Y, Yan H, Gu C: Mfsd2a is critical for the formation and function of the bloodbrain barrier. Nature 2014, 509:507-511

117. Agrawal S, Anderson P, Durbeej M, van Rooijen N, Ivars F, Opdenakker G, Sorokin LM: Dystroglycan is selectively cleaved at the parenchymal basement membrane at sites of leukocyte extravasation in experimental autoimmune encephalomyelitis. J Exp Med 2006, 203:1007-1019

118. Bell RD, Winkler EA, Singh I, Sagare AP, Deane R, Wu Z, Holtzman DM, Betsholtz C, Armulik A, Sallstrom J, Berk BC Zlokovic BV: Apolipoprotein E controls cerebrovascular integrity via cyclophilin A. Nature 2012, 485:512-516

119. Deane R, Du Yan S, Submamaryan RK, LaRue B, Jovanovic S, Hogg E, Welch D, Manness L, Lin C, Yu J, Zhu H, Ghiso J, Frangione B, Stern A, Schmidt AM, Armstrong DL, Arnold B, Liliensiek B, Nawroth P, Hofman F, Kindy M, Stern D, Zlokovic B: RAGE mediates amyloid-beta peptide transport across the blood-brain barrier and accumulation in brain. Nat Med 2003, 9:907-913

120. Montagne A, Nikolakopoulou AM, Huuskonen MT, Sagare AP, Lawson EJ, Lazic D, Rege SV, Grond A, Zuniga E, Barnes SR, Prince J, Sagare M, Hsu C-J, LaDu MJ, Jacobs RE, Zlokovic BV: APOE4 accelerates advanced-stage vascular and neurodegenerative disorder in old Alzheimer's mice via cyclophilin A independently of amyloid- $\beta$. Nat Aging 2021, 1:506-520 